\title{
Evaluation of skin phototoxicity of transdermally administered pharmaceuticals in Sprague-Dawley rats
}

Nam Hee Youn ${ }^{1}$, Eun Ji Kim', Jung-Sun Yi ${ }^{1}$, Joo Hwan Kim', Ye-Jin Cho ${ }^{2}$, Ki Taek Nam², Ki Sook Park ${ }^{1}$ and Jong Kwon Lee ${ }^{1 *}$ (D)

\begin{abstract}
Some drugs cause phototoxicity in humans when exposed to light, thus there is a need for an in vivo phototoxicity test to evaluate them. However, an in vivo phototoxicity test method to evaluate this has not been established. This study aimed to establish an in vivo phototoxicity test method for transdermally administered drugs. For this, we evaluated the phototoxicity using Sprague-Dawley (SD) rats for transdermal administered drugs and we studied the appropriate UVA dose using 8-methoxypsalen, which is a well-known phototoxic drug. We found that a UVA dose of $15 \mathrm{~J} / \mathrm{cm}^{2}$ was dose and time dependent response compared to other UVA doses. We performed the Minimum Erythema Dose (MED) test because UVB can cause skin irritation by itself and selected $0.01 \mathrm{~J} / \mathrm{cm}^{2}$ as an appropriate dose of UVB. Using the selected UVA and UVB doses, we performed a phototoxicity study of 6 pharmaceutical drugs, which included phototoxic and non-phototoxic drugs. As a result of the phototoxicity test, 100\% accuracy was obtained when compared with previous studies. In addition, we performed histopathology to confirm the new findings. We found that histopathology can be used as an additional indicator of phototoxicity test for transdermally administered drugs.
\end{abstract}

Keywords: Phototoxicity, In vivo test, Transdermal, Skin reaction, Histopathology

\section{Introduction}

Sunlight is comprised of visible light, infrared light, and ultraviolet light, each with a different range of wavelengths. Ultraviolet light has a shorter wavelength than visible light, has high energy, and a strong chemical action. It can cause various phototoxic reactions, including acute reactions such as erythema on the skin, as well as chronic reactions such as photoaging. Phototoxicity is mainly induced by exposure of photoreactive chemicals to ultraviolet rays [1]. These compounds are chemically activated by ultraviolet rays and bind to DNA in the cell nucleus, or

\footnotetext{
* Correspondence: jkleest@korea.kr

${ }^{1}$ Toxicological Evaluation and Research Department, National Institute of Food and Drug Safety Evaluation, Ministry of Food and Drug Safety, Cheongju 28159, Republic of Korea

Full list of author information is available at the end of the article
}

act on oxygen to form oxygen radicals or singlet oxygen molecules, which affect skin cells. Skin exposed to UV rays may exhibit symptoms such as erythema, eschar formation, edema, itchiness, stinging, and in severe cases, blistering or pigmentation may occur [1].

In addition, chemicals such as psoralen, quinolonebased antibiotics, anti-inflammatory drugs, and antidepressants among pharmaceuticals are reported to induce phototoxicity. Studies such as these are important in the evaluation and regulation of phototoxicity in pharmaceuticals [2-7]. The demand for evaluation of the phototoxicity evaluation of drugs is increasing, and the International Council for Harmonisation of Technical Requirements for Pharmaceuticals for Human Use (ICH) has established the Photosafety Evaluation of Pharmaceuticals (ICH S10), which presents general 
considerations for internationally agreed phototoxicity evaluation in Guidance on Nonclinical Safety Studies for the Conduct of Human Clinical Trials and Marketing Authorization for Pharmaceuticals (ICH M3, R2) $[8,9]$. However, ICH S10 doesn't describe a specific method of in vivo testing for evaluation of phototoxicity, so an in vivo testing method is necessary.

Selection of appropriate UV irradiation conditions is critical for both in vitro and in vivo phototoxicity testing. UVA doses ranging from 5 to $20 \mathrm{~J} / \mathrm{cm}^{2}$ are successfully used in current phototoxicity testing, according to $\mathrm{ICH}$ S10. UVA penetrates deeper than the epidermis and reaches the capillaries, but UVB is limited to the epidermis. Therefore, in order to testing transdermal drugs, the Minimum Erythema Dose (MED) test should be performed to select the minimum UVB dose with no erythema observed. In addition, the evaluation of in vivo phototoxicity is based on skin reaction of the skin, which is subjective and may vary depending on the tester because it relies on a gross examination method. Therefore, we suggest the selection of an appropriate dose of light for an in vivo phototoxicity test and the possibility of using histopathology as an additional indicator in evaluating phototoxicity.

\section{Methods/experimental}

\section{Chemicals}

The phototoxic drugs 8-Methoxy psoralen (8-MOP), Ibuprofen (IBF), Benzoyl peroxide (BPO), Ketoprofen (KPF), and Piroxicam (PXC) were used as positive substances and the non-phototoxic drug Sulisobenzone (SBZ) was used as a negative substance. A total of 6 substances were tested, and Acetone: DMSO (10:1) was used as the vehicle control (V.C). On the day of the test, test substances were prepared and the concentration of the substance was chosen as the highest concentration of soluble in vehicle control. 8-MOP, IBF, BPO, KPF, PXC, and SBZ were purchased from Sigma-Aldrich (St. Louis, MO, USA). All other reagents and materials were purchased from commercial sources.

\section{Animals}

Six-week-old female SpragueDawley (SD) rats (135-150 g, body weight) were purchased from Koatech (Pyeongtaek, Korea) and acclimated at an animal facility in the Korea Ministry of Food and Drug Safety (Certification Number: 1501MFDS08) in accordance with the Association for Assessment and Accreditation of Laboratory Animal Care (AAALAC) International Animal Care Policies (Accredited Unit, MFDS: Unit No. 001492). The animals were acclimated for at least 5 days prior to experimentation. During the acclimation period, clinical signs were checked once every day. SD rats were housed in polycarbonate cages with free access to food and water, and maintained on a $12 \mathrm{~h}$ dark/light cycle in a room with controlled temperature at $22 \pm 1{ }^{\circ} \mathrm{C}$ and with relative humidity of $50 \pm 10 \%$.

\section{Irradiation conditions}

A UV irradiation device (Bio-Spectra, Vilber lourmat, Germany) equipped with a UV tube (T-40.L, Vilber lourmat, Germany) was used as a light source. The UVA lamp, emitting 320-380 nm wavelengths, was used at an intensity of $2.2 \mathrm{~mW} / \mathrm{cm}^{2}$. The UVB lamp, emitting 290 $320 \mathrm{~nm}$ wavelengths, was used at an intensity of 2.2 $\mathrm{mW} / \mathrm{cm}^{2}$. In addition, the light irradiation intensity was checked using a UVP UVX radiometer (UVP, USA), UVP UVX-36 (UVP, USA), UVX-31 (UVP, USA).

\section{Preparation of animals}

One day before the test, rats were separated into groups and shaved. Weight variation did not exceed $20 \%$ of the mean weight and the rats were randomly separated into the test groups according to body weight. Three rats per group were used, and the rat number was assigned to 'test number-individual number'. Rats with abnormal skin lesions were excluded from the test. Rats were anesthetized intraperitoneally using sodium pentobarbital $(30 \mathrm{mg} / \mathrm{kg})$, and the hair of rats on the entire back of each rat was shaved with clippers. For convenience of observationof irradiation and phototoxic reaction, the irradiation site of the entire back of each rat was divided into 4 sites and spotted at $1.5 \times 1.5 \mathrm{~cm}^{2}$ using a skin marker. Except for this site, the aluminum foil was used to block the light. The same procedures were performed on the non-irradiated group as were performed on the irradiated group.

\section{Minimum erythema dose (MED) test}

The rats were irradiated with $0.01,0.03,0.05,0.1,0.15$, $0.2,0.25,0.3,0.35,0.4,0.45,0.5 \mathrm{~J} / \mathrm{cm}^{2} \mathrm{UVB}$. After 24,48 , and $72 \mathrm{~h}$ of irradiation, phototoxic skin reactions (erythema/eschar and edema) were evaluated and scored according to Draize's method (Table 1).

\section{Irradiation dose selection test}

This test was performed by transdermal administration of 8-MOP, which was prepared on the day of the test. We used the highest concentration of drug that was soluble in the vehicle control. The concentration of the test substance is as follows: 8-MOP 0.0001, 0.001, $0.01 \mathrm{w} / \mathrm{v}$ $\%$. The test substances were treated $100 \mu \mathrm{l}$ of 8 -MOP solution was applied to the application site $\left(1.5 \times 1.5 \mathrm{~cm}^{2}\right)$ on the back of the rat using a pipette. After $30 \mathrm{~min}$ of treatment with 8-MOP, UV irradiation was performed (UVA $5,10,15,20 \mathrm{~J} / \mathrm{cm}^{2}$; UVB $0.01 \mathrm{~J} / \mathrm{cm}^{2}$ ). After 24,48 , $72 \mathrm{~h}$ of irradiation, phototoxic skin reactions (erythema/ 
Table 1 Evaluation of skin reactions (Draize's Criteria)

\begin{tabular}{l}
\hline Score for erythema/eschar formation: \\
\hline 0;
\end{tabular}

eschar and edema) were evaluated and scored according to Draize's method (Table 1).

\section{Phototoxicity test of tansdermal administration by gross examination}

Five positive substances (8-MOP 0.0001, 0.001, $0.01 \mathrm{w} / \mathrm{v}$ $\%$; BPO 0.1, 1, $10 \mathrm{w} / \mathrm{v} \%$; IBF 0.1, 10, $25 \mathrm{w} / \mathrm{v} \%$; KPF 4, 40, $80 \mathrm{w} / \mathrm{v} \%$; PXC 0.1, 1, $2 \mathrm{w} / \mathrm{v} \%$ ) and one negative substance (SBZ $1 \mathrm{w} / \mathrm{v} \%$ ) were administered transdermally. The test substances were treated $100 \mu \mathrm{l}$ of 8 -MOP solution was applied to the application site $\left(1.5 \times 1.5 \mathrm{~cm}^{2}\right)$ on the back of the rat using a pipette. After $30 \mathrm{~min}$ of substance treatment, UV irradiation was performed (UVA $15 \mathrm{~J} / \mathrm{cm}^{2}$ and UVB $0.01 \mathrm{~J} / \mathrm{cm}^{2}$ ). After $24,48,72 \mathrm{~h}$ of irradiation, phototoxic skin reactions (erythema/eschar and edema) were evaluated and scored according to Draize's method (Table 1).

\section{Skin reaction evaluation}

After 24, 48, $72 \mathrm{~h}$ of irradiation, phototoxic skin reactions (erythema/eschar and edema formation) were evaluated and scored according to Draize's criteria (Table 1) [10]. For each test group, the skin reaction scores (erythema/ eschar and edema) of individual animals were summed for each site and the mean score was calculated according to the following equation:

Mean score $=$ Total of erythema and edema scores $/$ Number of animals tested [1].

A tested substance was judged to be phototoxic if the mean score of the UV-irradiated group or site was higher than that of the non-irradiated group or site at any observation period. In this study, no statistical analysis was performed.

\section{Histopathology of phototoxicity test}

Histopathology was performed with two representative samples each of the phototoxic drug 8-MOP, BPO, and KPF tests. On the last day of the test $(72 \mathrm{~h}$ after irradiation), the skin tissues of the rats were separated. Skin tissues were attached to thick paper in a flat orientation using a stapler, then fixed with $4 \%$ PFA, embedded in paraffin, sectioned, stained with hematoxylin and eosin (HE), and examined microscopically by a certified pathologist.

\section{Results}

\section{Minimum erythema dose (MED) test}

The results of the phototoxic reaction induced by UVB in SD rats are shown in Fig. 1. Phototoxic reactions were observed at doses of $0.03,0.05,0.1,0.15,0.2,0.25,0.3$, $0.35,0.4,0.45,0.5 \mathrm{~J} / \mathrm{cm}^{2}$ and no phototoxic reaction was observed at any time point at $0.01 \mathrm{~J} / \mathrm{cm}^{2}$. From these results, it was confirmed that the dose of irradiation that the phototoxicity is not induced by UVB is $0.01 \mathrm{~J} / \mathrm{cm}^{2}$ is the MED for UVB. Therefore, this dose was used in the irradiation dose selection test and the phototoxicity test of transdermal administration were used.

\section{Irradiation dose selection test}

The phototoxic reactions induced by $5-20 \mathrm{~J} / \mathrm{cm}^{2}$ of UVA and $0.01 \mathrm{~J} / \mathrm{cm}^{2}$ of UVB in SD rats are shown in Fig. 2. As shown in Fig. 2a, erythema of the irradiated site of V. C administration was observed at $20 \mathrm{~J} / \mathrm{cm}^{2}$, and edema was not observed at any concentration of $8-$ MOP at $5 \mathrm{~J} / \mathrm{cm}^{2}$, so dose-dependent results could not be confirmed. Therefore 5 and $20 \mathrm{~J} / \mathrm{cm}^{2}$ were excluded from further selection of UVA irradiation dose. As shown in Fig. 2b, the time-dependent tendency of the phototoxic reaction could not be observed at $10 \mathrm{~J} / \mathrm{cm}^{2}$,

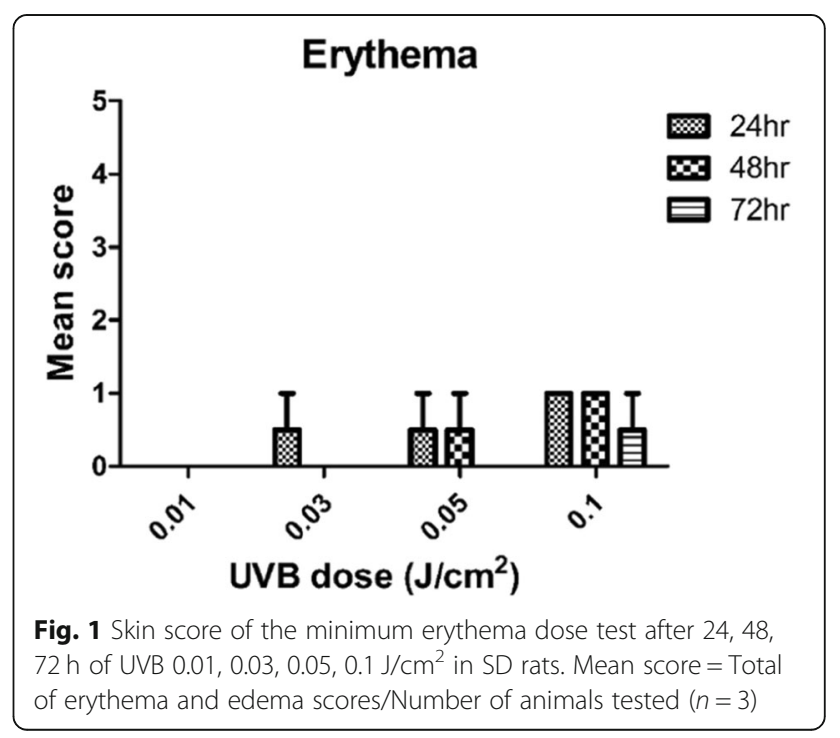




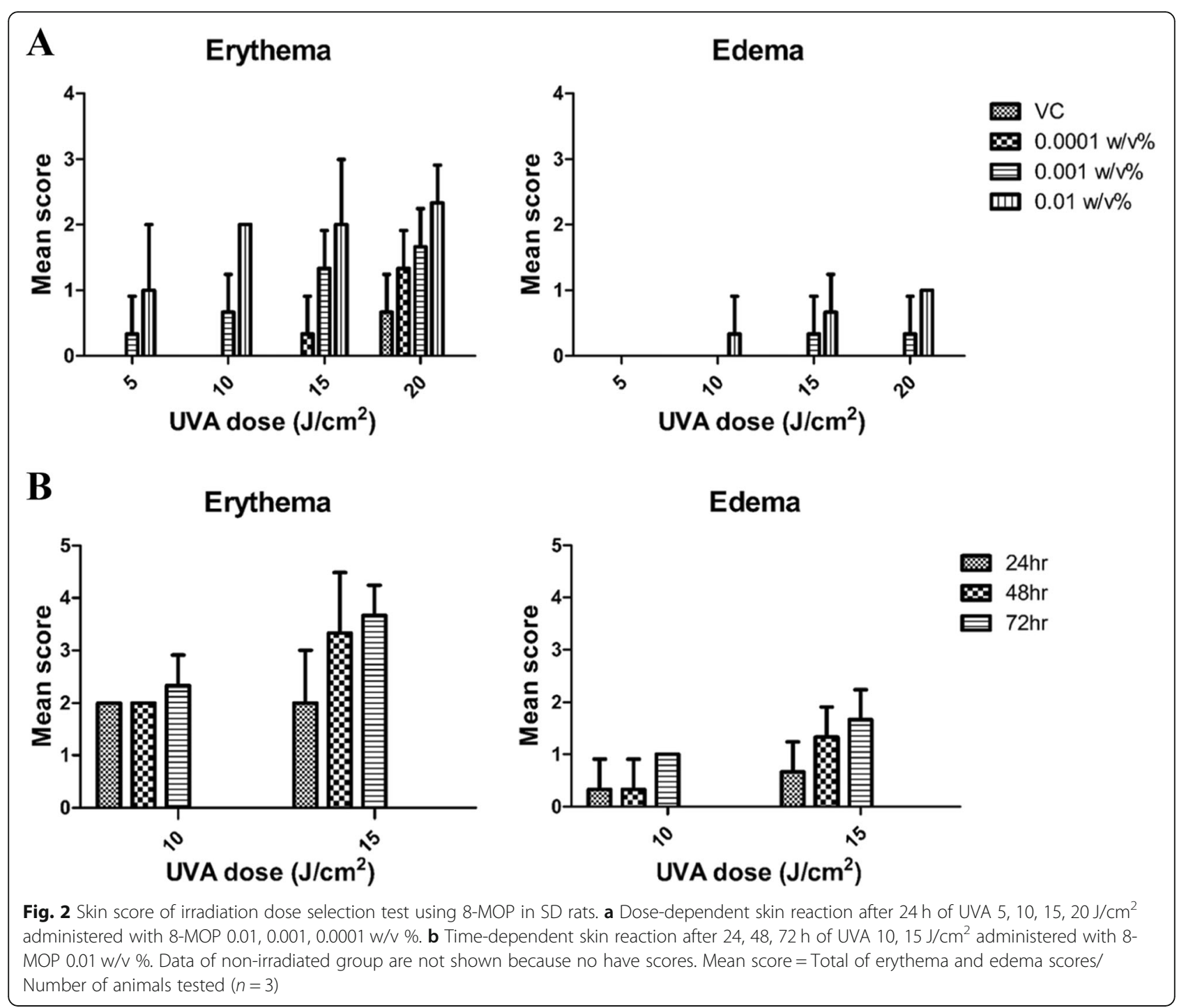

and the time-dependent tendency of both erythema and edema was observed at $15 \mathrm{~J} / \mathrm{cm}^{2}$. Based on these results, we selected $15 \mathrm{~J} / \mathrm{cm}^{2}$ as the appropriate UVA irradiation dose to identify dose and time dependent results.

\section{Phototoxicity test of tansdermal administration by gross examination}

The phototoxic reactions induced by $8-\mathrm{MOP}, \mathrm{BPO}, \mathrm{IBF}$, KPF, PXC, SBZ with UVA $15 \mathrm{~J} /$, UVB $0.01 \mathrm{~J} / \mathrm{cm}^{2}$ irradiation in SD rats are shown in Table 2 and Fig. 3 (Data shows only high concentration). In the 8-MOP irradiation group, erythema was observed at 0.0001 and 0.001 $\mathrm{w} / \mathrm{v} \%$, and erythema, eschar and edema were observed at $0.01 \mathrm{w} / \mathrm{v} \%$. In $\operatorname{IBF}(0.1,10,25 \mathrm{w} / \mathrm{v} \%)$ and PXC $(0.1,1$, $2 \mathrm{w} / \mathrm{v} \%$ ) irradiation group was observed erythema and edema were observed at all concentrations. In the BPO irradiation group, phototoxicity was not observed at 0.1 $\mathrm{w} / \mathrm{v} \%$ but erythema was observed at 1 and $10 \mathrm{w} / \mathrm{v} \%$. In the KPF irradiation group $(4,40,80 \mathrm{w} / \mathrm{v} \%)$ was observed erythema was observed at all concentrations and no phototoxic reaction was observed in the SBZ irradiation group $(1 \mathrm{w} / \mathrm{v} \%)$. No phototoxic reaction was observed in the non-irradiation group in all substances. These results were consistent with existing phototoxicity evaluation results, it was confirmed that it is consistent with the results of this study.

\section{Histopathology of phototoxicity test}

Representative histopathological photographs of two phototoxic drugs (BPO and KPF) are shown in Fig. 4. Table 3 (Data shows only high concentration) summarizes the findings. In the case of $\mathrm{BPO}$ and $\mathrm{KPF}$, which caused reactions that were ambiguous by gross examination, histopathology was performed to obtain accurate results, and representative phototoxic substance 8-MOP and $\mathrm{V} . \mathrm{C}$ were also performed. In the $\mathrm{V}$. C irradiation 
Table 2 Skin scores of SD rats after $48 \mathrm{~h}$ of UVA and UVB irradiation

\begin{tabular}{|c|c|c|c|c|}
\hline \multirow[t]{2}{*}{ Group } & \multirow{2}{*}{$\begin{array}{l}\text { Test } \\
\text { substance }\end{array}$} & \multirow{2}{*}{$\begin{array}{l}\text { Concentration } \\
\text { (w/v \%) }\end{array}$} & \multicolumn{2}{|c|}{ Mean score } \\
\hline & & & erythema & edema \\
\hline \multirow[t]{6}{*}{ UV(+) } & 8-MOP & 0.01 & 2.3 & 1.3 \\
\hline & $\mathrm{IBF}$ & 25 & 1.6 & 0.3 \\
\hline & $\mathrm{BPO}$ & 10 & 0.6 & 0 \\
\hline & KPF & 80 & 1.3 & 0 \\
\hline & PXC & 2 & 1.6 & 0 \\
\hline & SBZ & 1 & 0 & 0 \\
\hline \multirow[t]{6}{*}{ UV(-) } & 8-MOP & 0.01 & 0 & 0 \\
\hline & $\mathrm{IBF}$ & 25 & 0 & 0 \\
\hline & $\mathrm{BPO}$ & 10 & 0 & 0 \\
\hline & KPF & 80 & 0 & 0 \\
\hline & PXC & 2 & 0 & 0 \\
\hline & SBZ & 1 & 0 & 0 \\
\hline
\end{tabular}

There were three SD rats per group. No phototoxic response (erythema, edema) was observed in the non-irradiation site at all time

group, histopathology showed no phototoxic reaction so we observed unusual histopathological lesions. In the 8MOP irradiation group, the phototoxic reaction was observed in the irradiated rats that received low and medium concentrations. However, at high concentrations of 8-MOP, the epidermis was thickened due to the proliferation of the epidermal layer, and showed necrosis of the stratum corneum. In the BPO irradiation group, thickening of the epidermis was observed at low concentrations, and necrosis of the stratum corneum was observed at high concentrations. In the KPF irradiation group, necrosis of the stratum corneum was observed at low, medium, and high concentrations. In the 8-MOP, $\mathrm{BPO}$, and KPF treated irradiated groups showed normal histopathological lesions at all concentrations. Therefore 8-MOP, BPO, and KPF were judged to be phototoxic drugs.

\section{Discussion}

In this study, in order to selected the appropriate UV irradiation dose with an in vivo phototoxicity test and confirmed the phototoxicity of various drugs by two skin reaction evaluation methods. The UV irradiation dose suggested by ICH S10 is $5-20 \mathrm{~J} / \mathrm{cm}^{2}$, and the irradiation dose used by other research groups varies. Some UVA values used in other studies are $10.2 \mathrm{~J} / \mathrm{cm}^{2}$ for guinea pigs [11], $10 \mathrm{~J} / \mathrm{cm}^{2}$ for guinea pigs [12], $30 \mathrm{~J} / \mathrm{cm}^{2}$ for SD rats [13-15], and $10 \mathrm{~J} / \mathrm{cm}^{2}$ for SD rats [1]. Some UVB values used in other studies are $0.3 \mathrm{~J} / \mathrm{cm}^{2}$ for guinea pigs [12], $0.18 \mathrm{~J} / \mathrm{cm}^{2}$ for guinea pigs [16], $0.25 \mathrm{~J} / \mathrm{cm}^{2}$ for guinea pigs and $0.031 \mathrm{~J} / \mathrm{cm}^{2}$ for SD rats [1].

In order to select appropriate UVA and UVB doses to use in our phototoxicity test, an irradiation dose selection test (for UVA) and a MED test (for UVB) were performed. We found that the appropriate irradiation dose of UVA, dose and time-dependent response was $15 \mathrm{~J} /$ $\mathrm{cm}^{2}$. As a result of the MED test, we found that the appropriate irradiation dose of UVB dose not causing phototoxic reaction was $0.01 \mathrm{~J} / \mathrm{cm}^{2}$.

An in vivo transdermal phototoxicity test was performed using six test substances at the selected doses of

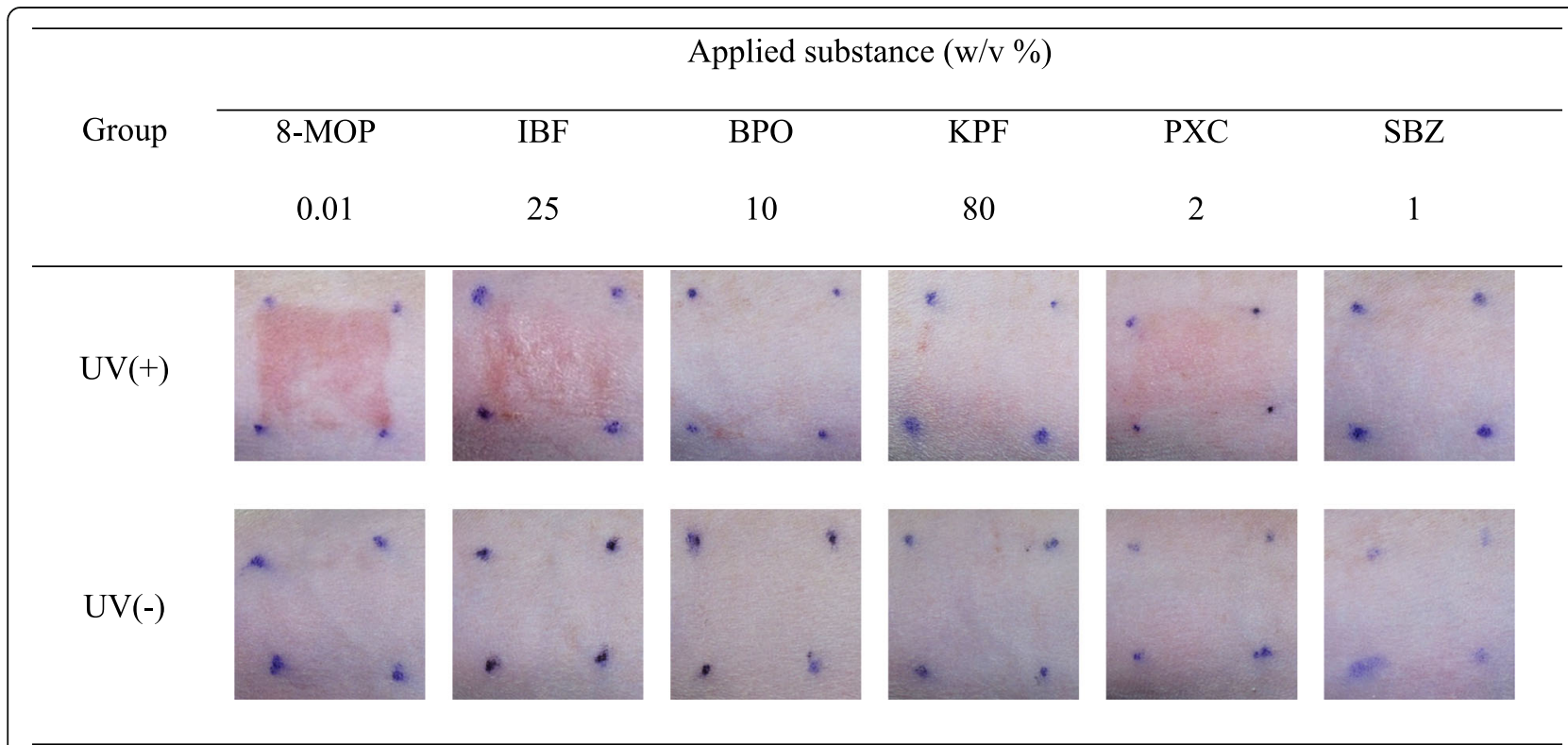

Fig. 3 Photographs of the skin reactions after $48 \mathrm{~h}$ of UVA $15 \mathrm{~J} / \mathrm{cm}^{2}$ and UVB $0.01 \mathrm{~J} / \mathrm{cm}^{2}$ in SD rats administered with 8-MOP, IBF, BPO, KPF, PXC, SBZ. Data shows only high concentration 


\section{A}

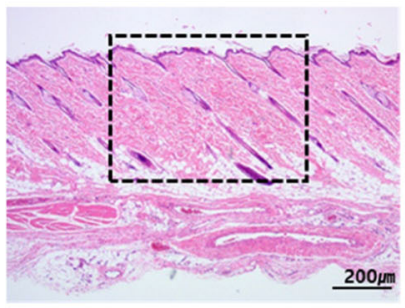

C

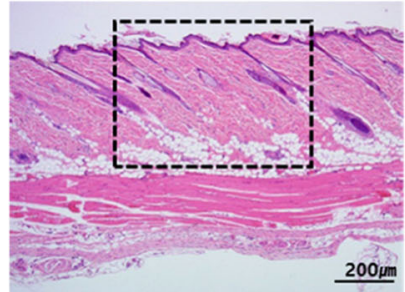

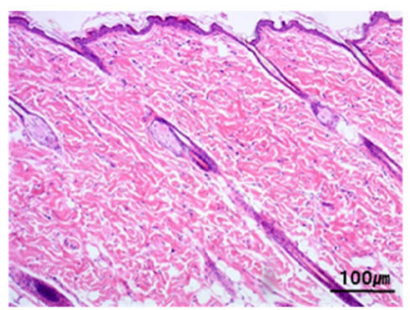

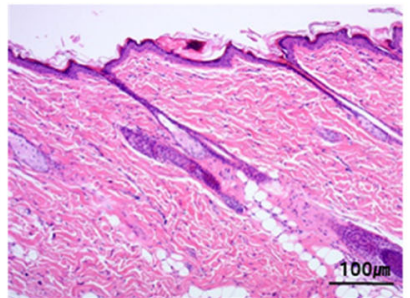

B
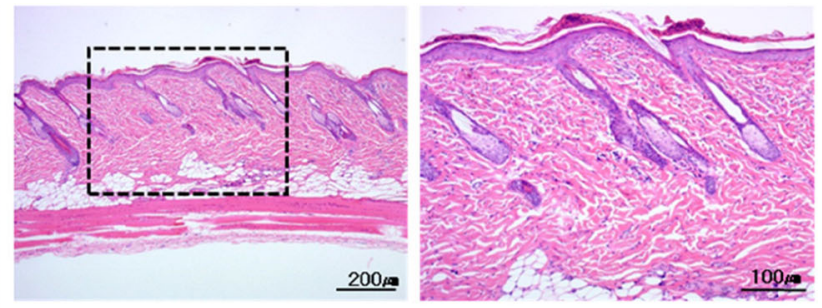

D

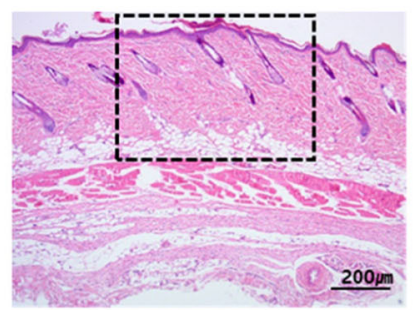

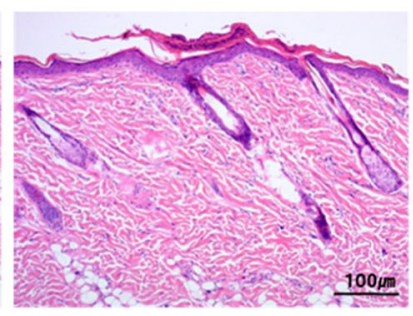

Fig. 4 Representative histopathological photographs of SD rat skin reactions after $72 \mathrm{~h}$ of UVA $15 \mathrm{~J} / \mathrm{cm}^{2}$ and UVB $0.01 \mathrm{~J} / \mathrm{cm}^{2}$. a V. C irradiation site. b 8 -MOP $0.01 \mathrm{w} / \mathrm{v} \%$ irradiation site. c BPO $10 \mathrm{w} / \mathrm{v} \%$ irradiation site. d KPF $80 \mathrm{w} / \mathrm{v} \%$ irradiation site

irradiation. Phototoxic reactions were observed with the five positive drugs (8-MOP, BPO, IBF, KPF, PXC) and judged as phototoxic drugs. No phototoxic reactions were observed with the negative control drug (SBZ) and judged as non-phototoxic drug. Phototoxic reactions (erythema, eschar, edema) was observed and scored according to Draize's criteria (Table 1) $[1,16,17]$.

In addition, we performed histopathology as an additional indicator of the phototoxicity test. We found histopathological lesions, caused by drugs, in the skin of rats treated with 8-MOP, BPO, and KPF. Thus, we confirmed the possibility of using histopathology as an additional indicator to supplement gross examination, which is the subjective reading of the phototoxicity test. From this results, the proposed photosafety evaluation on the basis of the in vivo phototoxicity for transdermal drugs.
Recently, interest in the photosafety of drugs has increased in both regulatory agencies and industry, and regulatory agencies have recommended the implementation of the 3Rs principle (refinement, reduction, and replacement). Considering these trends, the proposed test method would be useful for evaluating the in vivo phototoxicity of drugs.

\section{Conclusions}

Through this study, we found that suitable the irradiation doses in SD rats for testing the phototoxicity of drugs were UVA $15 \mathrm{~J} / \mathrm{cm}^{2}$ and UVB $0.01 \mathrm{~J} / \mathrm{cm}^{2}$. In addition, we showed that the use of histopathology as an additional indicator in the evaluation of phototoxicity allows more accurate and objective judgment. This confirmed the availability of the transdermal drug in vivo photosafety test method.

Table 3 Summary of the phototoxicity test

\begin{tabular}{lllll}
\hline $\begin{array}{l}\text { Test } \\
\text { substance }\end{array}$ & CAS.NO & Clinical $^{\mathbf{a}}$ & Judgement & Histopathology \\
\hline $8-M O P$ & & gross examination & Phototoxic \\
IBF & $298-81-7$ & Phototoxic & Phototoxic & Phototoxic \\
BPO & $15,687-27-1$ & Phototoxic & Phototoxic & Phototoxic \\
KPF & $94-36-0$ & Phototoxic & Weak-phototoxic & Phototoxic \\
PXC & $22,071-15-4$ & Phototoxic & Weak-phototoxic & Phototoxic \\
SBZ & $36,322-90-4$ & Phototoxic & Phototoxic & Non-phototoxic \\
\hline
\end{tabular}

ata from Yonezawa et al. 2015 [1] 


\section{Abbreviations}

8-MOP: 8-Methoxypsoralen; IBF: Ibuprofen; BPO: Benzoyl peroxide; KPF: Ketoprofen; PXC: Piroxicam; V.C: vehicle control; SD: Sprague-Dawley; UV: Ultraviolet; MED: Minimum Erythema Dose

\section{Acknowledgments}

Not applicable.

\section{Authors' contributions}

NHY and EJK performed the animal experiments. YJC and GTN performed the histopathology of the skin samples. JKL, KSP, JHK and JSK defined the principle of the study, and designed the experiments. NHY wrote and correct the manuscript. All authors read and approved the final manuscript.

\section{Funding}

This research was supported by the Ministry of Food and Drug Safety of Korea in 2018 (grant numbers 17181MFDS402).

\section{Availability of data and materials}

Available.

\section{Competing interests}

The authors declare that there are no financial conflicts of interest with respect to the publication of these results.

\section{Author details}

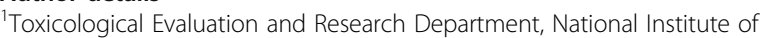
Food and Drug Safety Evaluation, Ministry of Food and Drug Safety, Cheongju 28159, Republic of Korea. ${ }^{2}$ Severance Biomedical Science Institute, Brain Korea 21 PLUS Project for Medical Science, Yonsei University College of Medicine, Seoul 03722, Republic of Korea.

Received: 13 August 2020 Accepted: 3 November 2020

Published online: 19 November 2020

\section{References}

1. Yonezawa Y, Ohsumi T, Miyashita T, Kataoka A, Hashimoto K, Nejishima H, et al. Evaluation of skin phototoxicity study using SD rats by transdermal and oral administration. J Toxicol Sci. 2015;40(6):667-83.

2. Spielmann $H$, Balls $M$, Brand $M$, Doring B, Holzhutter HG, Kalweit $S$, et al. EEC/COLIPA project on in vitro phototoxicity testing: first results obtained with a Balb/c 3T3 cell phototoxicity assay. Toxicol in Vitro. 1994;8(4):793-6.

3. Spielmann H, Balls M, Dupuis J, Pape WJ, Pechovitch G, de Silva O, et al. The international EU/COLIPA in vitro phototoxicity validation study: results of phase II (blind trial). Part 1: the 3T3 NRU phototoxicity test. Toxicol in Vitro. 1998;12:305-27.

4. Spielmann H, Muller L, Averbeck D, Balls M, Brendler-Schwaab S, Castell JV, et al. The second ECVAM workshop on phototoxicity testing: the report and recommendations of ECVAM workshop 42. Altern Lab Anim. 2000;28:777814.

5. Moore DE. Drug-induced cutaneous photosensitivity: incidence, mechanism, prevention and management. Drug Saf. 2002;25(5):345-72.

6. Jones PA, King AV. High throughput screening (HTS) for phototoxicity hazard using the in vitro 3 T3 neutral red uptake assay. Toxicol in Vitro. 2003; $17: 703-8$.

7. Neumann NJ, Blotz A, Wasinska-Kempka G, Rosenbruch M, Lehmann P, Ahr $\mathrm{HJ}$, et al. Evaluation of phototoxic and photoallergic potentials of 13 compounds by different in vitro and in vivo methods. J Photochem Photobiol B. 2005;79:25-34

8. International conference on harmonisation of technical requirements for registration of pharmaceuticals for human use. Photosafety Evaluation of Pharmaceuticals S10. 2013.

9. International conference on harmonisation of technical requirements for registration of pharmaceuticals for human use. Guidance on nonclinical safety studies for the conduct of human clinical trials and marketing authorization for pharmaceuticals M3 (R2). 2009

10. Draize JH. Dermal toxicity. In: Appraisal of the safety of chemicals in foods, drugs and cosmetics. Austin: The Association of Food and Drug Officials of the United States, Texas State Department of Health; 1959. p. 46-59.
11. Lkezawa Z, Kitamura K, Osawa J, Hariya T. Photosensitivity to piroxicam is induced by sensitization to thimerosal and thiosalicylate. J Invest Dermatol. 1992;98(6):918-22.

12. Nilsson R, Maurer T, Redmond N. A standard protocol for phototoxicity testing results from an interlaboratory study. Contact Dermatitis. 1993;28: 285-90.

13. Seto Y, Onoue S, Yamada S. In vitro/in vivo phototoxic risk assessments of griseofulvin based on photobiochemical and pharmacokinetic behaviors. Eur J Pharm Sci. 2009:38:104-11.

14. Seto $Y$, Ohtake H, Kato M, Onoue S. Phototoxic risk assessments on benzophenone derivatives: photobiochemical assessments and dermal cassette-dosing pharmacokinetic study. J Pharmacol Exp Ther. 2015;354: 195-202.

15. Kato M, Suzuki G, Ohtake H, Seto Y, Onoue S. New photosafety assessment strategy based on the photochemical and pharmacokinetic properties of both parent chemicals and metabolites. Drug Metab Dispos. 2015;43:181522.

16. Okumura Y, Yamauchi H, Takayama S, Kato H, Kokubu M. Phototoxicity study of a ketoprofen poultice in Guinea pigs. J Toxicol Sci. 2005;30:19-28.

17. Lee $\mathrm{SH}$. Evaluation of acute skin irritation and phototoxicity by aqueous and ethanol fractions of Angelica keiskei. Exp Ther Med. 2013;5:45-50.

\section{Publisher's Note}

Springer Nature remains neutral with regard to jurisdictional claims in published maps and institutional affiliations.
Ready to submit your research? Choose BMC and benefit from:

- fast, convenient online submission

- thorough peer review by experienced researchers in your field

- rapid publication on acceptance

- support for research data, including large and complex data types

- gold Open Access which fosters wider collaboration and increased citations

- maximum visibility for your research: over $100 \mathrm{M}$ website views per year

At BMC, research is always in progress.

Learn more biomedcentral.com/submissions 